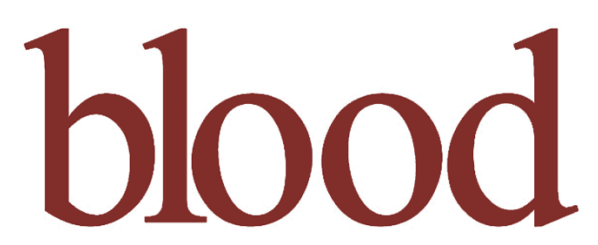

2008 112: 4158-4169

Prepublished online August 7, 2008;

doi:10.1182/blood-2008-02-140814

\title{
Wiskott-Aldrich syndrome protein deficiency in B cells results in impaired peripheral homeostasis
}

Almut Meyer-Bahlburg, Shirly Becker-Herman, Stephanie Humblet-Baron, Socheath Khim, Michele Weber, Gerben Bouma, Adrian J. Thrasher, Facundo D. Batista and David J. Rawlings

Updated information and services can be found at:

http://bloodjournal.hematologylibrary.org/content/112/10/4158.full.html

Articles on similar topics can be found in the following Blood collections

Immunobiology (4699 articles)

Information about reproducing this article in parts or in its entirety may be found online at:

http://bloodjournal.hematologylibrary.org/site/misc/rights.xhtml\#repub_requests

Information about ordering reprints may be found online at:

http://bloodjournal.hematologylibrary.org/site/misc/rights.xhtml\#reprints

Information about subscriptions and ASH membership may be found online at:

http://bloodjournal.hematologylibrary.org/site/subscriptions/index.xhtml

Blood (print ISSN 0006-4971, online ISSN 1528-0020), is published weekly by the American Society of Hematology, 2021 L St, NW, Suite 900 ,

Washington DC 20036.

Copyright 2011 by The American Society of Hematology; all rights reserved.

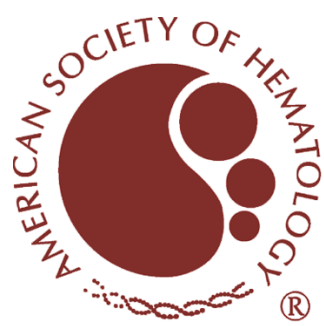




\title{
Wiskott-Aldrich syndrome protein deficiency in B cells results in impaired peripheral homeostasis
}

\author{
*Almut Meyer-Bahlburg, ${ }^{1}$ *Shirly Becker-Herman, ${ }^{1}$ Stephanie Humblet-Baron, ${ }^{2}$ Socheath Khim, ${ }^{1}$ Michele Weber, ${ }^{3}$ \\ Gerben Bouma, ${ }^{4}$ Adrian J. Thrasher, ${ }^{4}$ Facundo D. Batista, ${ }^{3}$ and David J. Rawlings ${ }^{1,5}$ \\ 1Department of Pediatrics, Seattle Children's Hospital Research Institute, WA; ${ }^{2}$ Center for Cellular and Molecular Therapy, GIGA-R, University of Liege, Liege, \\ Belgium; ${ }^{2}$ Lymphocyte Interaction Laboratory, Cancer Research UK London Research Institute, London, United Kingdom; ${ }^{4}$ Centre for Immunodeficiency, \\ University College London and Great Ormond Street Hospital for Children National Health Service (NHS) Trust, London, United Kingdom; and ${ }^{5}$ Department of \\ Immunology, University of Washington School of Medicine, Seattle
}

\begin{abstract}
To more precisely identify the B-cell phenotype in Wiskott-Aldrich syndrome (WAS), we used 3 distinct murine in vivo models to define the cell intrinsic requirements for WAS protein (WASp) in central versus peripheral B-cell development. Whereas WASp is dispensable for early bone marrow B-cell development, WASp deficiency results in a marked reduction in each of the major mature peripheral B-cell subsets, exerting the greatest impact on marginal
\end{abstract}

zone and B1a B cells. Using in vivo bromodeoxyuridine labeling and in vitro functional assays, we show that these deficits reflect altered peripheral homeostasis, partially resulting from an impairment in integrin function, rather than a developmental defect. Consistent with these observations, we also show that: (1) WASp expression levels increase with cell maturity, peaking in those subsets exhibiting the greatest sensitivity to WASp defi- ciency; (2) WASp ${ }^{+}$murine B cells exhibit a marked selective advantage beginning at the late transitional B-cell stage; and (3) a similar in vivo selective advantage is manifest by mature WASp ${ }^{+}$human $B$ cells. Together, our data provide a better understanding of the clinical phenotype of WAS and suggest that gene therapy might be a useful approach to rescue altered B-cell homeostasis in this disease. (Blood. 2008; 112:4158-4169)

\section{Introduction}

Wiskott-Aldrich syndrome (WAS) is an X-linked immunodeficiency disorder characterized by recurrent infections, microthrombocytopenia, and eczema. In addition, WAS is associated with an increased incidence of autoimmune disease and hematologic malignancies, especially B-cell lymphomas. ${ }^{1}$ Affected patients are susceptible to bacterial, viral, and fungal infections, secondary to defects in both cellular and humoral immunity. Lymphopenia is a common finding in WAS patients from infancy on, mainly because of reduced numbers of $\mathrm{T}$ cells, whereas $\mathrm{B}$ cells are normal or moderately decreased. ${ }^{2,3}$ Antibody responses are adequate to some antigens and insufficient to others. In particular, WAS patients fail to respond to polysaccharide antigens and are highly susceptible to infections with Streptococcus pneumoniae. ${ }^{4}$

The affected gene, WASP, encodes a multidomain protein, WASp, which is exclusively expressed in hematopoietic cells and is the founding member of a family of proteins involved in the transduction of signals to the actin cytoskeleton. ${ }^{5}$ The actin cytoskeleton plays a crucial role in cell adhesion and migration, antigen receptor surface assembly and turnover, and formation of the T-cell immunologic synapse on cell stimulation. Each of these pathways can be affected in WAS and contribute to the clinical phenotype. Several studies have demonstrated defective macrophage and DC migration and adhesion, ${ }^{4}$ and more recent studies also suggest impaired trafficking of $\mathrm{T}$ and $\mathrm{B}$ cells as well as neutrophils. ${ }^{6-9}$ Both human and murine $\mathrm{WASp}^{-1-} \mathrm{T}$ cells exhibit defective actin polymerization, impaired T-cell receptor cap-

Submitted February 19, 2008; accepted July 20, 2008. Prepublished online as Blood First Edition paper, August 7, 2008; DOI 10.1182/blood-2008-02140814.

${ }^{*}$ A.M.-B. and S.B.-H. contributed equally to this work.

An Inside Blood analysis of this article appears at the front of this issue. ping, ${ }^{10-13}$ reduced ability to produce interleukin-2, and decreased proliferation in response to anti-CD3 stimulation in vitro. ${ }^{14}$

Studies investigating B-cell function in both human and murine WAS have been more limited in scope and have led to various results and interpretations. Study of Epstein-Barr virustransformed B-cell lines derived from WAS patients showed defective actin polymerization. ${ }^{15} \mathrm{Ca}^{++}$-flux upon B-cell receptor (BCR) stimulation of human $\mathrm{B}$ cells has been reported to be normal ${ }^{16}$ or reduced. ${ }^{17}$ In WASp ${ }^{-1-}$ mice, the proliferative response to BCR engagement was either slightly reduced ${ }^{13}$ or normal. ${ }^{12,13}$ The latter study also showed normal capping of B cells in response to BCR stimulation. Westerberg et al demonstrated impaired polarization, spreading, homotypic aggregation, and microvilli formation in response to CD40 stimulation, and defective migration to $\mathrm{CXCL13}$ in $\mathrm{WASp}^{-/-}$primary murine B cells. ${ }^{8,18}$ In addition, both WAS patients and $\mathrm{WASp}^{-/-}$mice exhibit a marked reduction in the number of splenic marginal zone (MZ) B cells. ${ }^{8,19}$ These findings are consistent with the lack of antibody responses to pneumococcal polysaccharides in humans ${ }^{2}$ and decreased antibody response to TI immunization with dextran in mice. ${ }^{8}$

In an effort to better understand the relative contributions of the B-cell lineage to the immunodeficiency of WAS, we performed a detailed analysis of each of the major B-cell developmental subsets in WASp ${ }^{-1-}$ animals. We also used 3 independent in vivo models to precisely characterize the requirement for WASp in the central versus peripheral B-cell compartments. Our results demonstrate 
specific, B cell-intrinsic defects in cell numbers within each of the mature B-cell developmental subsets. Further, using a combination of in vitro functional assays and in vivo labeling studies, our data demonstrate that these changes reflect altered B lymphoid homeostasis rather than a developmental defect. Finally, we show that WASp-expressing B cells exhibit a strong selective advantage over WASp-deficient B cells in both humans and mice.

\section{Methods}

\section{Animal studies}

Six- to 8-week-old C57BL/6, $\mu \mathrm{MT}$ and $\mathrm{WASp}^{-1-}$ (F10 on a C57BL/6 background) mice were maintained in the SPF animal facility at Children's Hospital (Seattle, WA) and handled according to Institutional Animal Care and Use Committee-approved protocols. Bone marrow (BM) was harvested from $\mathrm{WASp}^{-1-}$ or wild-type (WT) mice, and $5 \times 10^{6} \mathrm{BM}$ cells were transplanted intravenously into sublethally irradiated (500 cGy) $\mu \mathrm{MT}$ recipient mice.

\section{Reagents and antibodies}

Reagents used in this study include PyroninY and 4,6-diamidinophenylindole:2 $\mathrm{HCl}$ (DAPI) from Invitrogen (Carlsbad, CA). Antimurine antibodies included CD24, CD21, B220, CD5, CD43, and CD1d from BD Biosciences PharMingen (San Diego, CA), BP1 from eBioscience (San Diego, CA), CD23 from Invitrogen, IgM from Southern Biotechnology Associates (Birmingham, AL), and CD19 from BioLegend (San Diego, CA). Antihuman antibodies included CD24, CD38, and $\operatorname{IgD}$ from BD Biosciences PharMingen, CD19 from BioLegend, and IgM from Southern Biotechnology Associates. Purified polyclonal rabbit anti-WASp antibody was a kind gift from Dr H. Ochs (University of Washington, Seattle, WA). Cy5 antirabbit polyclonal IgG was purchased from Jackson ImmunoResearch Laboratories (West Grove, PA).

\section{Flow cytometry}

Single cell suspensions were incubated with fluorescently labeled antibodies for 20 minutes at $4^{\circ} \mathrm{C}$. Data were collected on a FACSCalibur or LSR II flow cytometer (BD Biosciences, San Jose, CA) and analyzed using FlowJo software (TreeStar, Ashland, OR). For cell-cycle analysis, cells were surface stained, fixed overnight with $2 \%$ paraformaldehyde, washed, and incubated for 30 minutes with $1 \mu \mathrm{g} / \mathrm{mL}$ of DAPI in phosphate-buffered saline with $0.1 \%$ fetal calf serum and $0.1 \%$ Triton X-100. A total of $1.5 \mu \mathrm{g} / \mathrm{mL}$ of PyroninY was added immediately before analysis. Intracellular WASp staining was performed according to instructions for the BD Biosciences PharMingen Fixation/Permeabilization Solution Kit. Absolute cell numbers were determined using a Neubauer Chamber and calculated based on relative percentages obtained from fluorescence-activated cell sorter (FACS) analysis.

\section{Bromodeoxyuridine incorporation}

Mice were fed with bromodeoxyuridine (BrdU) continuously via the drinking water ( $1 \mu \mathrm{g} / \mathrm{mL} \mathrm{BrdU}$, Sigma-Aldrich, St Louis, MO; and 10\% sucrose) and killed at indicated time points. Cells from BM, spleen, and peritoneal cavity were surface stained, then fixed and permeabilized, treated with DNase, and stained with anti-BrdU FITC (BrdU Kit from BD Biosciences).

\section{Immunologic synapse analysis}

Lipid bilayers with or without glycosylphosphatidylinositol-linked intercellular adhesion molecule-1 (ICAM-1) were prepared by liposome spreading as previously described. ${ }^{20}$ Briefly, Alexa 633 -streptavidin was incorporated into the bilayers and used to load anti-BCR at a density of 150 molecules/ $\mu \mathrm{m}^{2}$, and Alexa532-labeled glycosylphosphatidylinositol-linked ICAM-1 was either added or not at 80 molecules $/ \mu \mathrm{m}^{2}$. B cells were settled on lipid bilayers, and differential interference contrast images of several independent areas were taken after 20 minutes. Central supramolecular activation cluster (cSMAC) frequency was determined by counting B cells aggregating anti-BCR and forming a cSMAC as a percentage of total B cells. Immunologic synapse (IS) frequency reflects B cells forming cSMACs and pSMACS as a percentage of all B cells forming cSMACs. The B-cell contact area was quantified by interference reflection microscopy (IRM) as described. ${ }^{21}$

\section{Human peripheral blood}

Peripheral blood was collected from a WAS patient and healthy persons after informed consent was obtained in accordance with the Declaration of Helsinki and the Institutional Review Board guidelines of the Children's Hospital and Regional Medical Center (Seattle, WA). Peripheral blood mononuclear cells were isolated using Ficoll-Hypaque (GE Healthcare, Little Chalfont, United Kingdom) gradient centrifugation.

\section{Results}

\section{Specific defects in mature B-cell subsets in WASp ${ }^{-/-}$mice}

$\mathrm{WASp}^{-1-}$ mice were described almost a decade ago. ${ }^{12,13}$ Whereas a recent report has demonstrated a reduction in splenic MZ B-cell numbers, ${ }^{8}$ to date, only relatively limited analysis of various B-cell compartments in $\mathrm{WASp}^{-1-}$ mice has been performed. We therefore evaluated each of the B-cell developmental populations within the $\mathrm{BM}$, spleen, and peritoneal cavity in WT versus $\mathrm{WASp}^{-/-}$mice. We first analyzed central B-cell development within the BM according to Hardy's classification ${ }^{22}$ (Figure S3A, available on the Blood website; see the Supplemental Materials link at the top of the online article). No significant differences were observed in the pro B-cell to immature B-cell stages (fractions A-E; Figures 1A, S1A). In contrast, both the absolute and relative number of recirculating, $\mathrm{IgD}^{+} \mathrm{B}$ cells (fraction $\mathrm{F}$ ) were consistently reduced $(\sim 1.8$-fold) in $\mathrm{WASp}^{-1-}$ mice (Figures 1A, S1A).

Immature B cells emigrate from the BM to the spleen as transitional B cells (transitional 1 [T1] and 2 [T2]) where, in response to microenvironmental cues, they differentiate into either follicular mature (FM) B cells, or marginal zone precursor (MZP) and MZ B cells. As shown in Figure $1 \mathrm{~B}, \mathrm{~T} 1$ cells are $\mathrm{CD} 21^{\text {low }} \mathrm{CD} 24^{\mathrm{hi}}$, $\mathrm{T} 2$ cells $\mathrm{CD} 21^{\text {int }} \mathrm{CD} 24^{\text {hi }}$, and $\mathrm{FM} B$ cells are $\mathrm{CD} 21^{\text {int }} \mathrm{CD} 24^{\text {int }}$. $\mathrm{CD} 21^{\text {hi }} \mathrm{CD} 24^{\text {hi }} \mathrm{MZP} / \mathrm{MZ} \mathrm{B}$ cells can be further distinguished by CD23: MZP are CD23 ${ }^{\text {hi }}$, whereas MZ B cells are CD23 ${ }^{\text {low. Total }}$ B-cell numbers, as well as the absolute number of FM B cells, were comparable between WT and $\mathrm{WASp}^{-1-}$ mice (Figure 1B,C). However, we observed a significant increase in relative and absolute numbers of T1 B cells ( $\sim 1.5$-fold, Figures 1B,C, S1B,C). In addition and consistent with previous studies, ${ }^{8} \mathrm{MZP}$ and MZ B-cell numbers were reduced 3 -fold. In addition, cells with a $\mathrm{CD} 21^{\text {hi }} \mathrm{CD} 1 \mathrm{~d}^{\text {hi }}$ phenotype, independent markers for the MZ lineage, were similarly reduced (Figure 1B).

Next, we analyzed B1 cells in the peritoneal cavity that are crucial for TI immune responses. They can be further separated by $\mathrm{CD} 5$ into $\mathrm{B} 1 \mathrm{a}\left(\mathrm{CD} 5^{\mathrm{hi}}\right)$ and $\mathrm{B} 1 \mathrm{~b}\left(\mathrm{CD} 5^{\text {low }}\right)$ cells. Our analysis identified a relative increase in $\mathrm{B} 1 \mathrm{~b}$ cells (not shown) that reflected a relative and an absolute decrease in the number of B1a cells (Figure 1D,E; $\sim 2$-fold reduction). We also determined the frequency of BM B1 cell precursors ${ }^{23}$ and found no differences (Figure S1D).

We conclude from this analysis that WASp deficiency does not affect early BM B-cell development but significantly impacts specific B-cell developmental subpopulations in the spleen and 
A

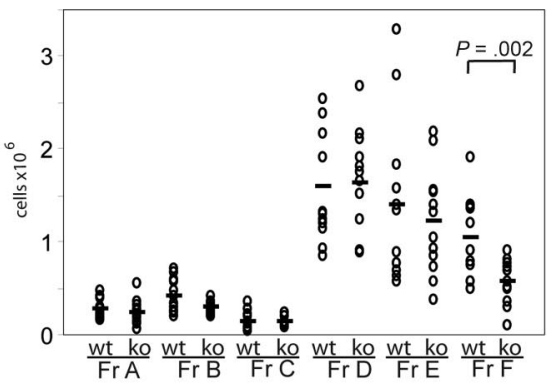

B
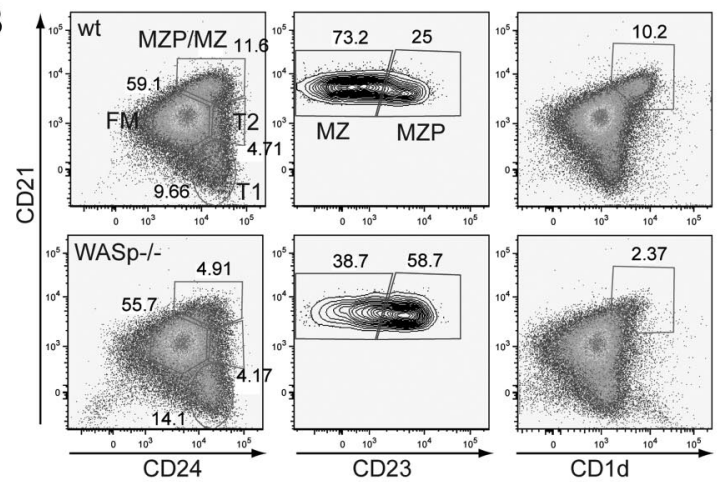

C

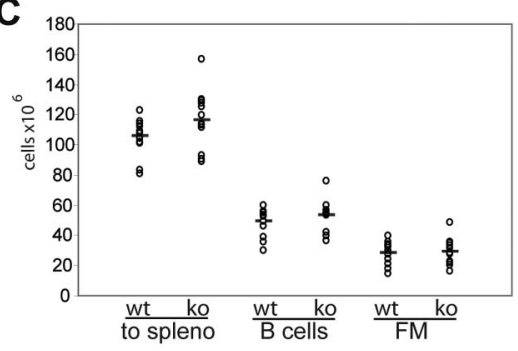

D
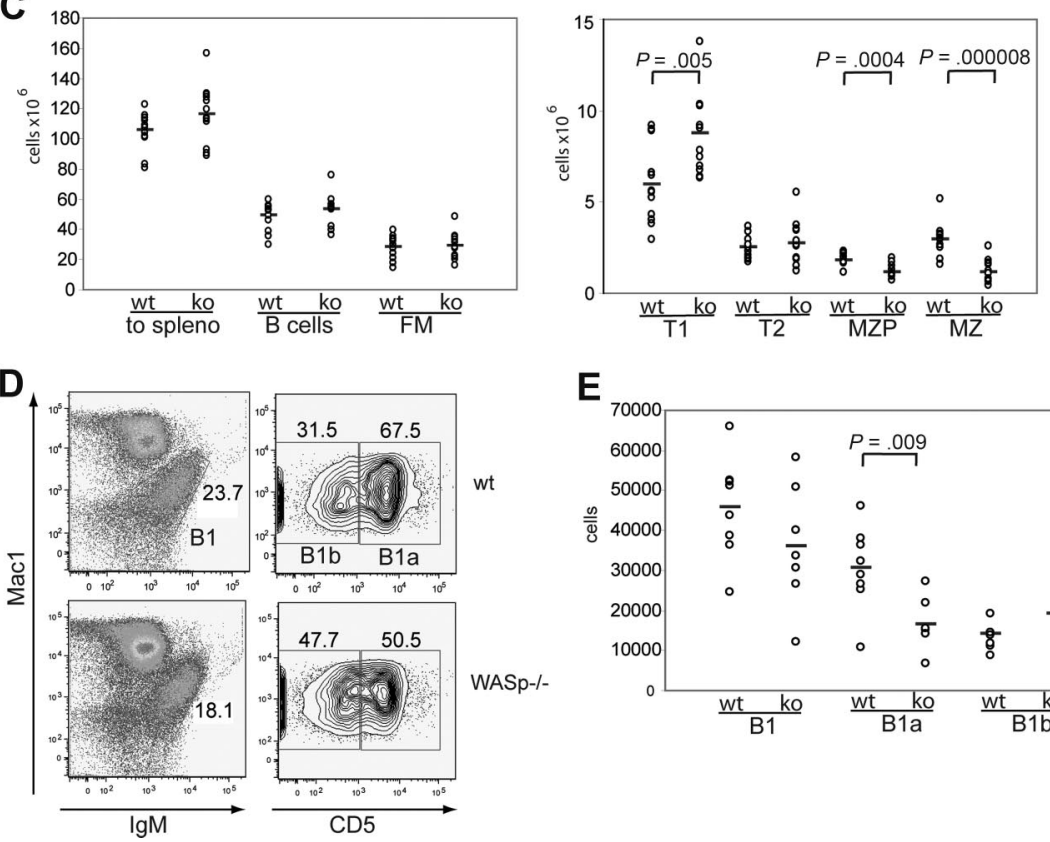

$\mathbf{E}$

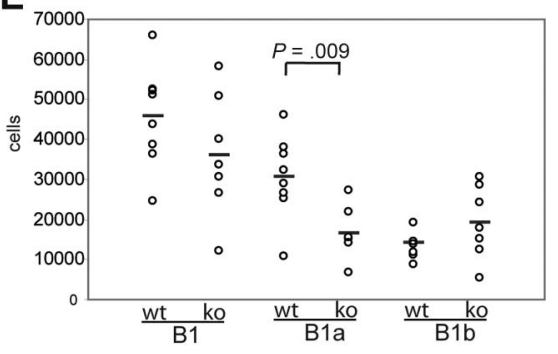

Figure 1. The B-cell phenotype in WASp-deficient mice. (A) BM was stained for expression of B220, CD43, IgM, BP1, CD24, CD19, and IgD and developmental stages determined according to the Hardy classification. Absolute numbers for each fraction $(\mathrm{Fr}) \mathrm{A}$ through $\mathrm{F}$ are shown in WT versus WASp ${ }^{-1-}$ mice (ko) $(n=12)$. $(B, C)$ Splenocytes were stained for expression of B220, CD19, CD24, CD21, CD23, and CD1d and B-cell subsets analyzed. (B) Representative FACS blot gated on $\mathrm{B}^{2} 2{ }^{+} \mathrm{CD} 19^{+}$cells in a WT versus $\mathrm{WASp}^{-1-}$ mouse. (C) Absolute numbers of splenic B-cell subsets from WT versus WASp ${ }^{-1-}$ mice $(n=12)$. (D,E) Peritoneal B cells were stained for IgM, CD5, and Mac1. (D) Representative FACS blot of gating B1 cells in a WT and a WASp ${ }^{-/-}$ mouse. (E) Absolute numbers of $B 1, B 1 a$, and $B 1 b$ cells in WT $(n=8)$ versus WASp ${ }^{-/-}$mice $(n=7)$. peritoneal cavity and leads to a reduction of the number of recirculating $\mathrm{B}$ cells within the $\mathrm{BM}$.

\section{B-cell defects in WASp ${ }^{-I-}$ mice are B-cell intrinsic}

To directly determine whether the observed B-cell phenotype, including the loss of MZ B cells in WASp ${ }^{-1-}$ mice, is the result of a B cell-intrinsic defect, we carried out a series of transplantation experiments using B cell-deficient, $\mu$ MT-recipient animals. Sublethally irradiated $\mu \mathrm{MT}$ mice (500 cGy) were transplanted with BM cells from $\mathrm{WASp}^{-1-}$ or littermate control mice. Analysis of peripheral blood at 5.5 weeks after transplantation showed a significant increase in the percentage of circulating T1 B cells and a parallel reduction in mature $\mathrm{B}$ cells in recipients of $\mathrm{WASp}^{-1-} \mathrm{BM}$ (Figure 2B; of note, MZP/MZ B cells are not present in peripheral blood). Six weeks after transplantation, recipient mice were killed and B-cell subsets in BM, spleen, or peritoneal cavity were analyzed by FACS. Notably, in recipients of $\mathrm{WASp}^{-1-}$ marrow, all peripheral B lineage cells, but less than $10 \%$ of splenic T cells, were donor derived as assessed using intracellular WASp staining (not depicted). We observed no significant differences in either absolute number or relative composition of early to immature BM $\mathrm{B}$ lineage cells (fractions A-E). However, as in $\mathrm{WASp}^{-1-}$ mice, there was an approximately 2 -fold decrease in recirculating $\operatorname{IgD}^{+}$ BM B cells (fraction F, Figures 2A, S2A). In addition, the absolute number of splenic B cells was significantly reduced, and this change was reflected by a reduction in both $\mathrm{T} 2(\sim 2$-fold $)$ and MZP/MZ B cells (each 3-fold; Figure 2C). The percentage of T1 $\mathrm{B}$ cells was significantly increased, although this change was not 
From bloodjournal.hematologylibrary.org by FREDERIC BARON on January 26, 2012. For personal use only.

A

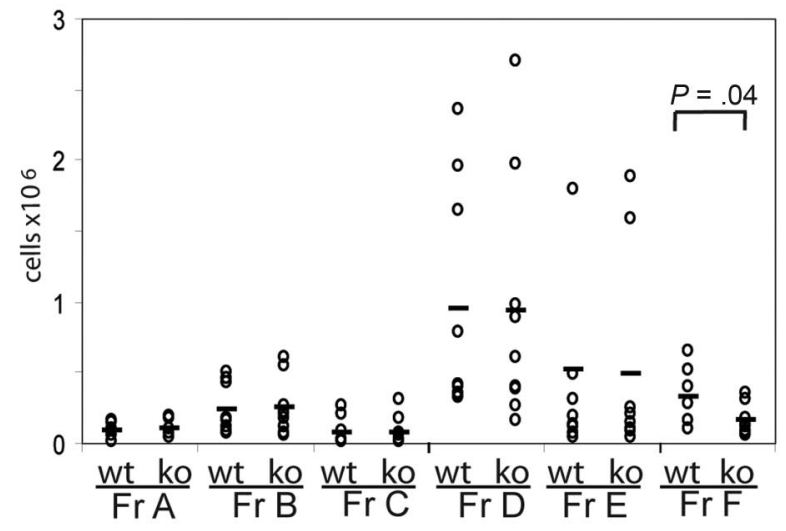

C

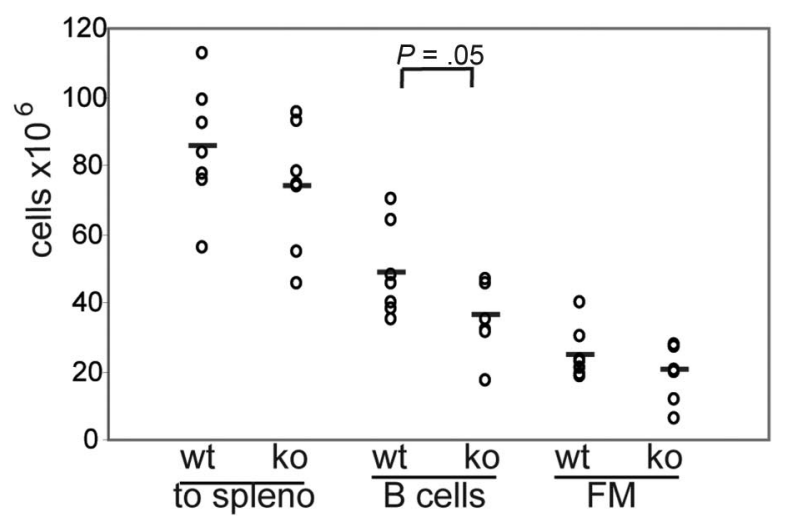

D

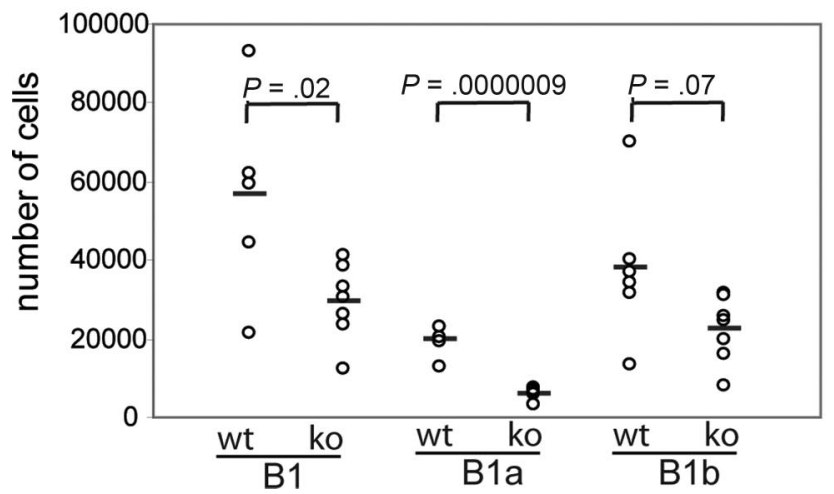

B
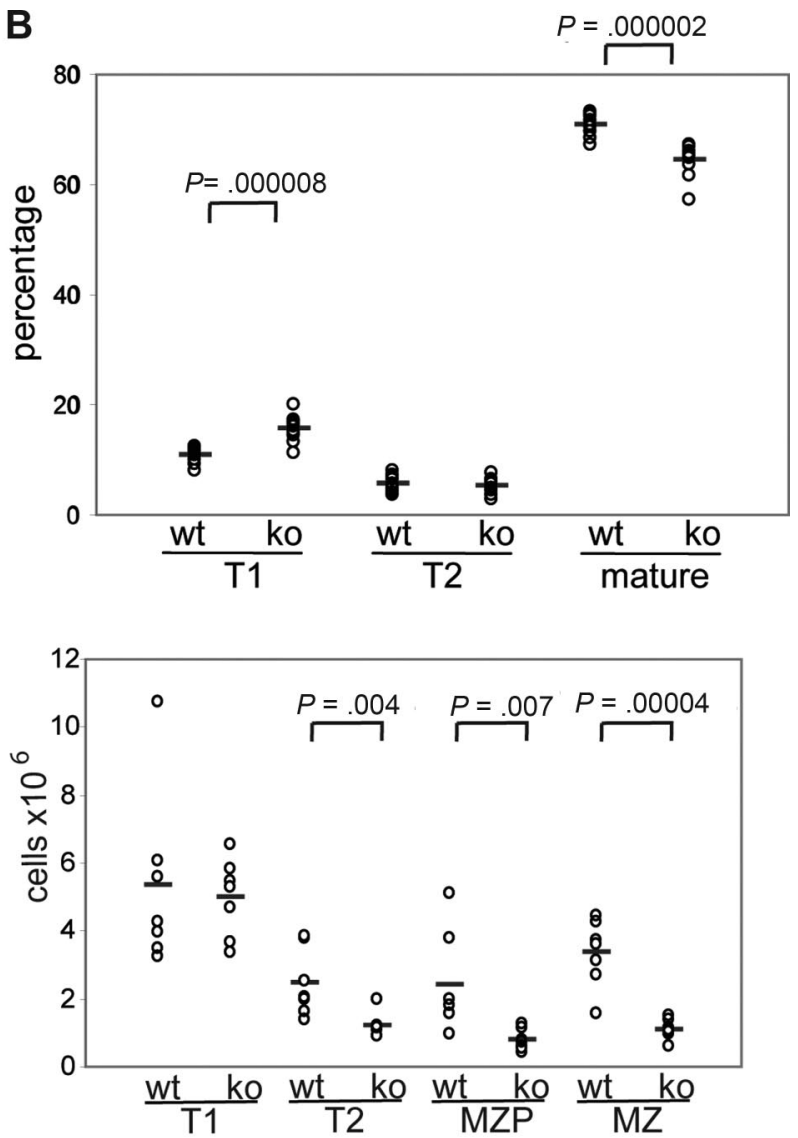

Figure 2. The WASp-deficient B-cell phenotype is B cell-intrinsic. BM from WT or WASp ${ }^{-1-}$ mice was transplanted into sublethally irradiated $\mu M T$ mice. Recipient mice were killed 6 weeks after transplantation, and B-cell subsets in BM, spleen, and peritoneal cavity were analyzed. Shown are absolute numbers for (A) BM ( $\mathrm{n}=9$ recipient mice), (C) spleen $(n=7)$, and (D) peritoneal cavity $(n=7)$ and the relative percentage of subsets in (B) peripheral blood $(n=12)$.

reflected in absolute T1 B-cell numbers (Figures 2C, S2B). Analysis of peritoneal $\mathrm{B}$ cells showed a decrease in the absolute number of $\mathrm{B} 1 \mathrm{a} \mathrm{B}$ cells consistent with the finding in $\mathrm{WASp}^{-1-}$ mice (Figure 2D). These combined data demonstrate that each of the changes in the B-cell compartment in $\mathrm{WASp}^{-1-}$ mice reflects a B cell-intrinsic defect.

\section{The relative level of WASp expression mirrors its functional requirement in $B$-cell subsets}

We next asked whether the observed B-cell phenotype correlates with the relative level of WASp expression. BM, splenic, and peritoneal B cells were stained intracellularly with an antibody specific for WASp in addition to the previously mentioned cell surface markers. In the BM, expression of WASp was similar in fractions $A$ to $E$ but increased significantly in recirculating $\operatorname{IgD}{ }^{+}$ $\mathrm{B}$ cells (fraction F; Figure $3 \mathrm{~A}$ ). Within the spleen, expression of WASp was highest in MZP and MZ B cells (Figure 3B), whereas in the peritoneal cavity, B1a cells expressed the highest levels of WASp (Figure 3C). These results suggest that those B-cell subsets that normally express higher levels of WASp are more sensitive to WASp deficiency.

\section{WASp ${ }^{+} \mathrm{B}$ cells exhibit a selective advantage beginning at the late transitional stage}

We next analyzed intracellular WASp expression within B-cell subsets isolated from WASp ${ }^{+-}$female mice. This approach allowed us 
A

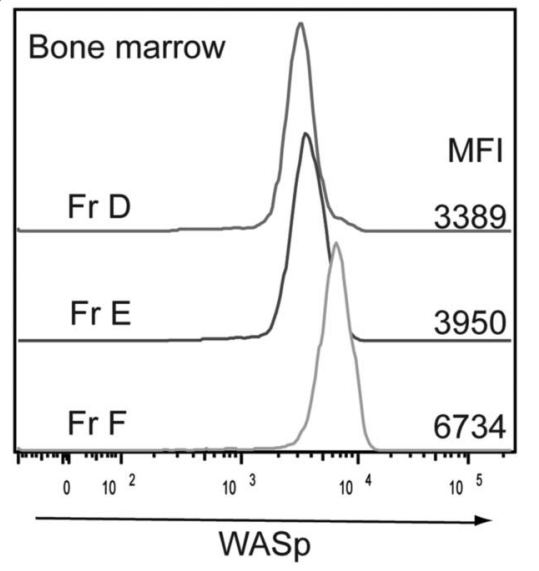

B

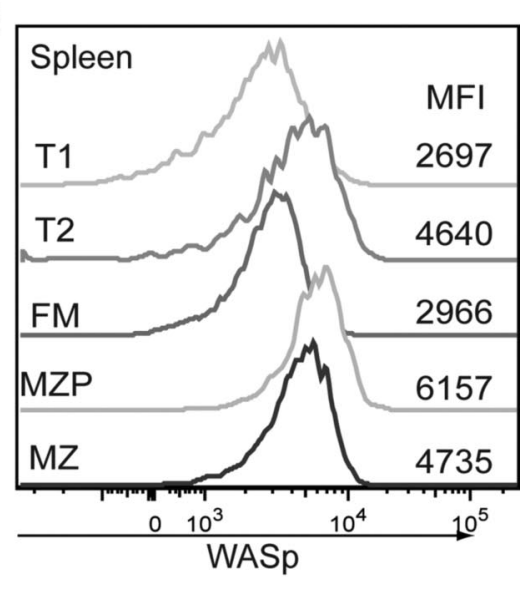

Figure 3. Relative WASp expression levels in distinct B-cell subsets. B cells in different lymphoid compartments from a WT mouse were stained for WASp expression in addition to surface markers to determine B-cell subpopulations. Relative WASp expression and mean fluorescent intensity are shown for each of the B-cell subsets derived from (A) BM, (B) spleen, and (C) peritoneal cavity. Data shown are representative of more than 5 individual mice.

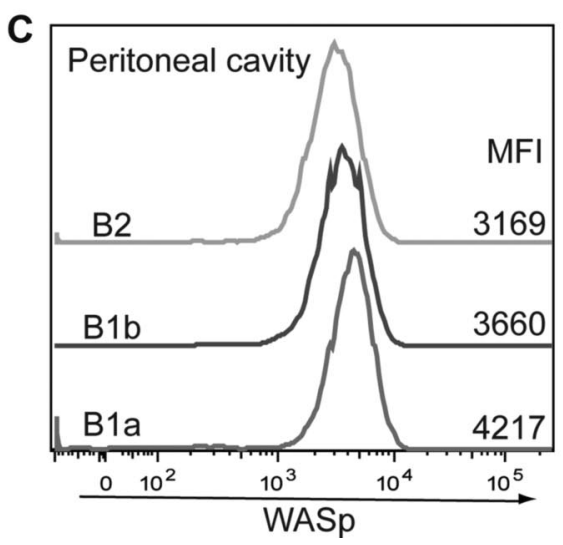

to identify developmental stages at which $\mathrm{WASp}^{+} \mathrm{B}$ cells might manifest a selective advantage. We observed little or no evidence of selective advantage for $\mathrm{WASp}^{+} \mathrm{B}$ cells during $\mathrm{BM}$ development: approximately $55 \%$ of cells within each of the BM fractions A, B, D, and E expressed WASp (Figures 4A, S3C). Interestingly, we observed a specific reduction in $\mathrm{WASp}^{+}$cells in $\mathrm{BM}$ fraction $\mathrm{C}$ (only $\sim 33 \%$ of fraction $\mathrm{C}$ were $\mathrm{WASp}^{+}$). However, analysis in WT mice also showed reduced expression of WASp specific to fraction C (only $\sim 40 \%$ $\mathrm{WASp}^{+}$; Figure S3B). This change probably reflects an artifact secondary to the rapid proliferation of fraction $\mathrm{C}$ pre-B cells.

In contrast to $\mathrm{BM}$ B-cell development, the percentage of $\mathrm{WASp}^{+} \mathrm{B}$ cells increased progressively within the peripheral B-cell compartment. This change was first evident within T2 $\mathrm{B}$ cells and was most prominent in MZP/MZ B cells: Whereas only approximately $55 \%$ of $\mathrm{T} 1 \mathrm{~B}$ cells were $\mathrm{WASp}^{+}, 65 \%$ of $\mathrm{T} 2$ and $\mathrm{FM}$ $\mathrm{B}$ cells and more than $85 \%$ of $\mathrm{MZP} / \mathrm{MZ} \mathrm{B}$ cells were $\mathrm{WASp}^{+}$ (Figure 4A-C). In addition, approximately $70 \%$ of recirculating $\mathrm{IgD}^{+} \mathrm{B}$ cells in the BM (fraction F) expressed WASp. Within the B1 B-cell compartment, the majority of cells expressed WASp with the greatest skewing present within B1a cells: approximately $80 \%$ of $\mathrm{B} 1 \mathrm{a}$ cells were $\mathrm{WASp}^{+}$compared with approximately $70 \%$ of B1b cells (Figure 4D,E).

These combined observations suggest that there is little or no selective advantage for $\mathrm{WASp}^{+} \mathrm{B}$ cells in early B-cell development, and clearly demonstrate selective advantage for $\mathrm{WASp}^{+}$cells within the peripheral B-cell compartment beginning at the T2 B-cell stage.

\section{WASp deficiency primarily impacts peripheral B-cell homeostasis}

The results described so far suggest that $\mathrm{WASp}^{-1-} \mathrm{B}$ cells manifest either a survival/homeostatic defect or a specific developmental defect(s) leading, ultimately, to severely reduced numbers of mature MZ, B1a, and recirculating naive B cells.

Notch signaling plays a crucial role in MZ B-cell development. ${ }^{24}$ Because this subset is most severely affected in WASp ${ }^{-1-}$ mice, we determined the expression of the Notch target genes, Hes1 and Deltex1,25 in FM and MZ B cells from WT versus $\mathrm{WASp}^{-1-}$ mice. Hes1, but not Deltex1, expression levels were consistently reduced in $\mathrm{WASp}^{-1-} \mathrm{B}$ cells suggestive of a partial defect in Notch2 signaling (Figure S4). However, when we determined Hes1 expression in FM and MZ B cells derived from chimeric BM transplantation recipients, no differences were observed (Figure S4A,B), indicating that the alteration in Hes1 levels in WASp ${ }^{-1-}$ mice does not reflect a B cell-intrinsic defect.

To directly differentiate between a survival/homeostatic versus a developmental defect, we performed in vivo BrdU labeling experiments. BrdU is incorporated into dividing cells during $\mathrm{S}$ phase of the cell cycle. Therefore, if a developmental defect were to account for the observed phenotype, we hypothesized that fewer BrdU-labeled mature $\mathrm{B}$ cells would be present in WASp ${ }^{-1-}$ mice (as there would be fewer newly formed, recently divided cells). In contrast, if this phenotype reflected an alteration in B-cell homeostasis, turnover rates would be predicted to be higher, resulting in equal or increased numbers of $\mathrm{BrdU}^{+}$ cells in $\mathrm{WASp}^{-1-}$ versus WT mice.

Experimental animals fed BrdU via the drinking water were killed at day 3 or 7 and B cells analyzed for BrdU incorporation. As expected (based on the lack of evidence for an early BM developmental defect), BrdU labeling was similar in early BM stages (fractions A-E) and only slightly increased in T1 and T2 B cells (day 3; Figure 5A; data not shown). In contrast, a significantly greater fraction of splenic FM, MZP, and MZ B cells 
From bloodjournal.hematologylibrary.org by FREDERIC BARON on January 26, 2012. For personal use only.

A Bone marrow:

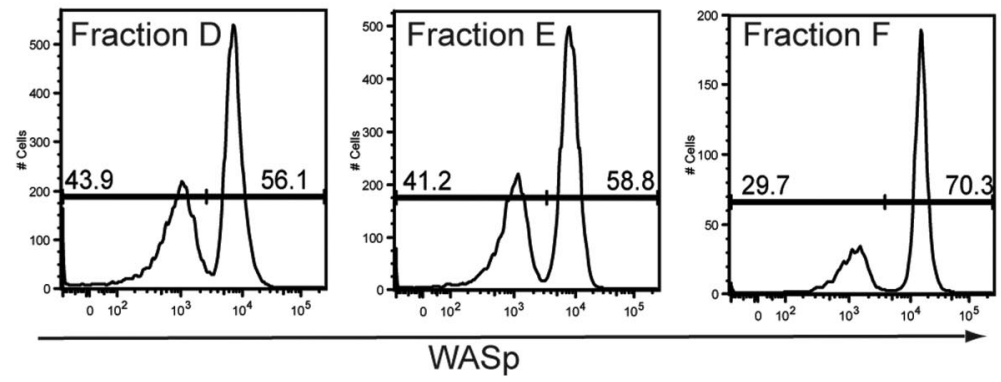

B Spleen:
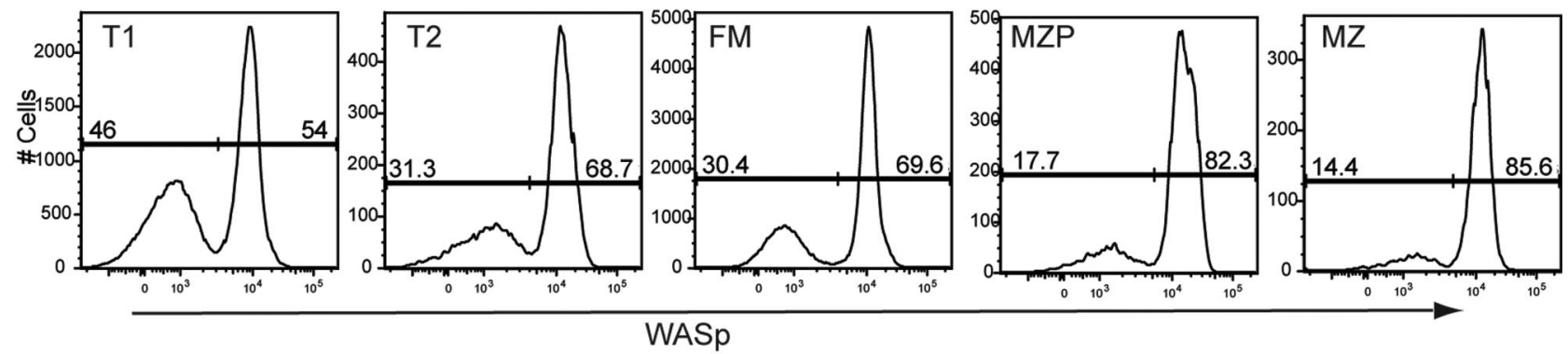

C

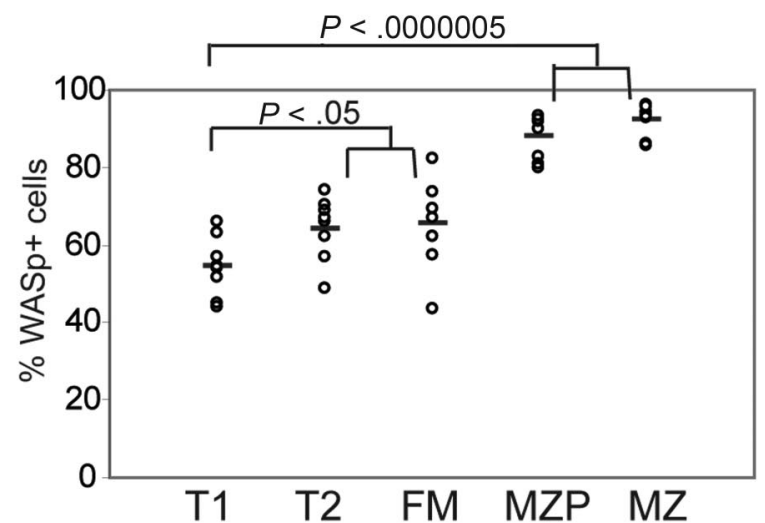

D Peritoneal cavity:

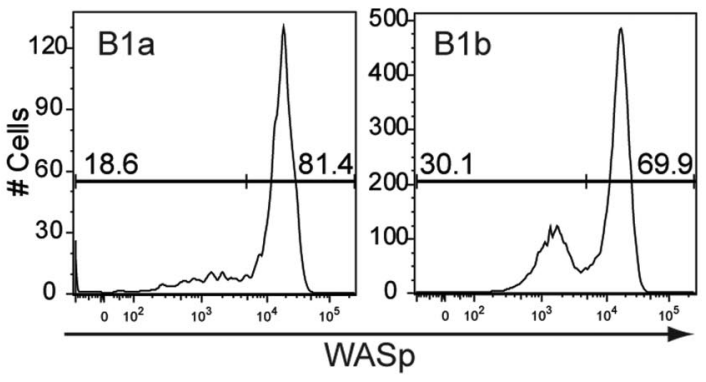

E

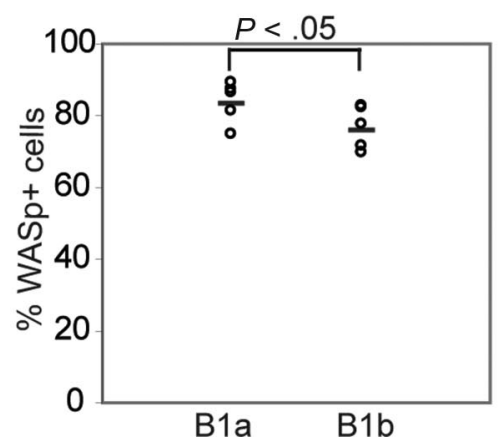

Figure 4. WASp+ B cells exhibit a selective advantage beginning at the late transitional B-cell stage. Expression of WASp was determined in B-cell subsets derived from $\mathrm{BM}$, spleen, and peritoneal cavity in female WASp heterozygous mice. Representative example of staining in (A) BM, (B) spleen, and (D) peritoneal cavity. Percentage of WASp-positive B cells in each subset in (C) spleen $(n=8)$ and $(E)$ peritoneal cavity $(n=6)$.

were $\mathrm{BrdU}^{+}$in $\mathrm{WASp}^{-/-}$mice (Figure 5A). In addition, recirculating $B$ cells exhibited faster labeling on days 3 and 7, respectively (Figure 5A; data not shown). B1a and B1b populations exhibited significantly more $\mathrm{BrdU}^{+}$cells on day 3 and a trend for greater labeling at day 7 (Figure 5B). Comparing the BrdU labeling kinetics, it was evident that the turnover rate of $\mathrm{WASp}^{-1-} \mathrm{B}$ cells was significantly higher beyond the T1 B-cell stage. Notably, the absolute number of MZ B cells that incorporated BrdU was similar in both strains (Figure 5C), supporting the conclusion that the overall reduction in $\mathrm{MZ} \mathrm{B}$-cell numbers in $\mathrm{WASp}^{-/-}$mice was 

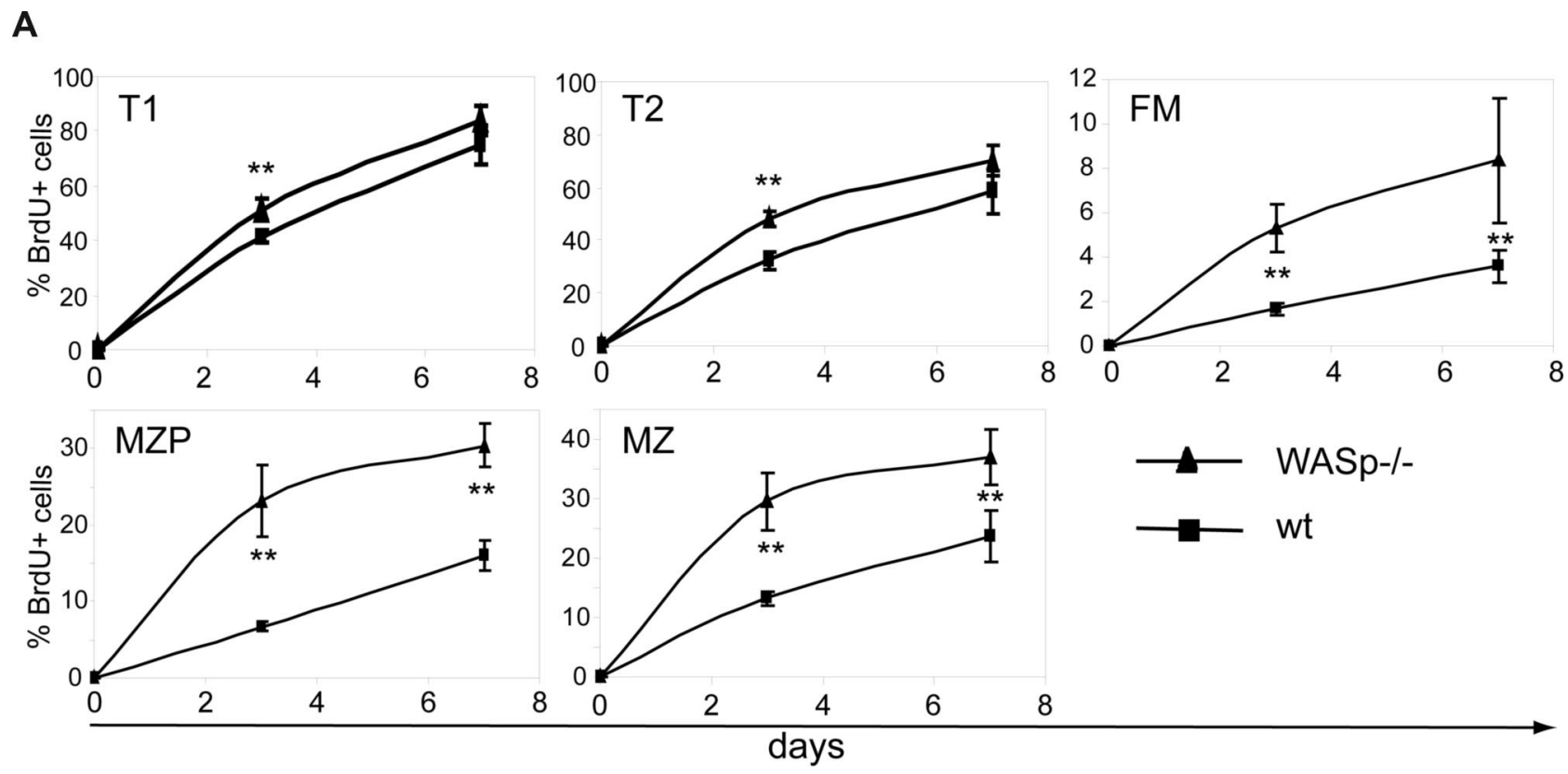

B

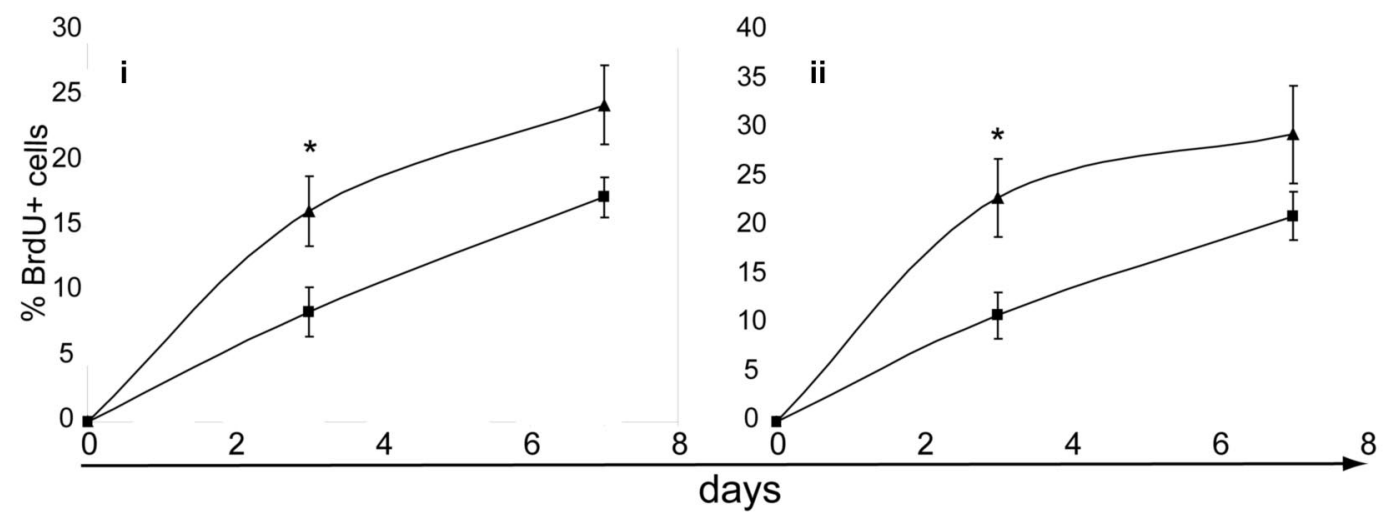

C

D
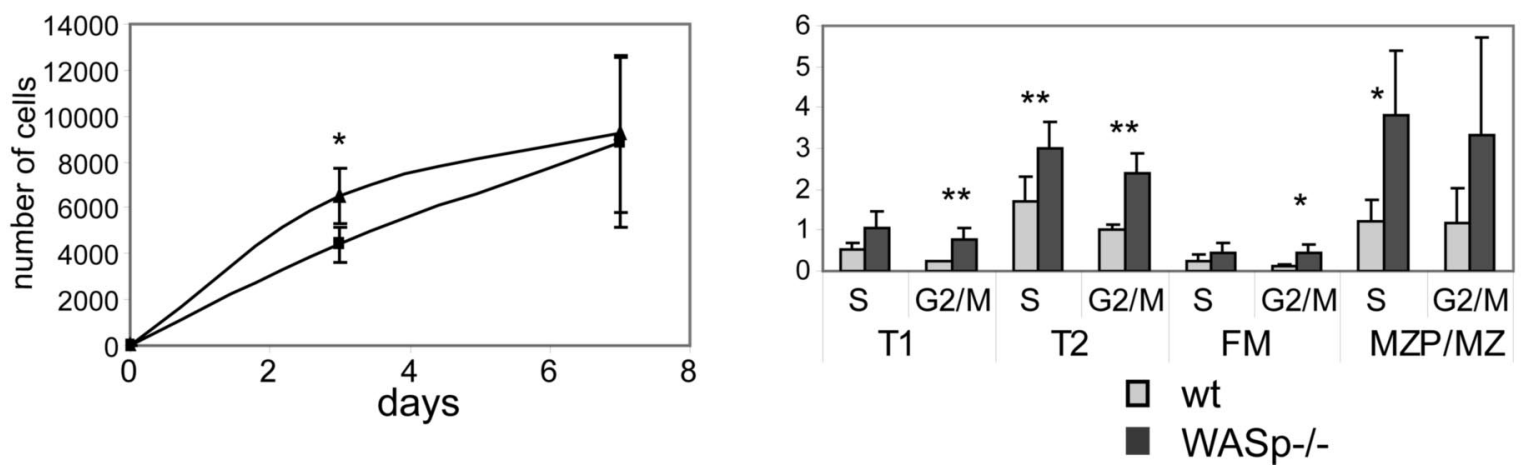

Figure 5. B cells in WASp-deficient mice exhibit a higher turnover rate. (A-C) WT and WASp ${ }^{-1-}$ mice were continuously fed BrdU via the drinking water for up to 7 days. Mice were killed on day 3 or 7 and splenocytes stained for BrdU in addition to surface makers to identify B-cell subsets. Percentage of BrdU ${ }^{+}$cells in (A) splenic and (B) peritoneal B-cell subsets. (C) Absolute numbers of BrdU ${ }^{+} \mathrm{MZ}$ B cells in WT versus WASp ${ }^{-1-}$ mice. Data shown reflect the average of 3 mice per time point and are representative of 2 independent experiments. ${ }^{*} P \leq .05$. (D) For cell-cycle analysis, splenocytes from WT or WASp ${ }^{-1-}$ mice were stained with PyroninY and DAPI in addition to surface markers. Data show the percentage of cells in either $\mathrm{S}-$ or $\mathrm{G}_{2} / \mathrm{M}$ phase of the cell cycle (average of 3 mice) from one of 3 independent experiments. ${ }^{\star} P \leq .05$; ${ }^{\star \star} P \leq .01$.

unlikely to be due to a developmental defect. We also performed pulse-chase studies, by feeding BrdU for 7 days followed by analysis of splenic B cells on days 7 and 14 after labeling. As expected, $\mathrm{BrdU}^{+} \mathrm{FM}$ and $\mathrm{MZP} / \mathrm{MZ} \mathrm{B}$ cells turned over significantly more rapidly in $\mathrm{WASp}^{-1-}$ mice (Figure S5A). Consistent with a higher turnover rate in each of the mature B-cell subsets, a significantly greater percentage of all peripheral B cells had entered cell cycle in $\mathrm{WASp}^{-/-}$mice $\left(\mathrm{S}\right.$ and $\mathrm{G}_{2} / \mathrm{M}$ phase, Figure $\left.5 \mathrm{D}\right)$.

Survival of mature resting B cells in the periphery depends on coordinate signals mediated via the BCR and B-cell activating factor of the TNF family receptor (BAFF-R). We used several approaches to determine whether defects in survival signaling 
might account for altered homeostasis of $\mathrm{WASp}^{-/-} \mathrm{B}$ cells. A previous report suggested that lower expression of the prosurvival protein, Bcl-2, correlated with increased apoptosis in $\mathrm{WASp}^{-/-}$ human B cells. ${ }^{26}$ We observed no difference in Bcl-2 expression in B-cell subsets from WT versus WASp ${ }^{-1-}$ mice (Figure S5B). We also observed no differences in cell survival in response to BCR engagement in FACS-sorted WT versus $\mathrm{WASp}^{-1-} \mathrm{T} 1$ or FM B cells; or in survival of unstimulated or BAFF-treated T1, T2, FM, or MZP/MZ B cells (measured at 24 hours; Figure S5C). BAFF-R engagement promotes processing of NF- $\mathrm{B} 2$ p100 and enhances the expression of survival genes. We observed similar BAFF-R levels in WT and $\mathrm{WASp}^{-1-} \mathrm{B}$ cells and similar processing of $\mathrm{p} 100$ to 552 after BAFF stimulation (Figure S5D,E). Akt plays a key role in B-cell survival and is up-regulated in MZ B cells. ${ }^{27,28}$ A comparison of p-AKT basally or after BCR engagement in each peripheral B-cell subset identified no differences between WT and $\mathrm{WASp}^{-1-}$ cells (Figure S5F). We conclude that alterations in B-cell homeostasis in $\mathrm{WASp}^{-1-}$ mice are largely independent of B cellintrinsic survival signals mediated via the BCR and BAFF-R.

Because integrins play an important role in the positioning of MZ B cells, ${ }^{29}$ we investigated whether the observed phenotype of $\mathrm{WASp}^{-1-}$ mice could be explained by an underlying defect in their ability to activate integrins. The formation of the mature IS after BCR stimulation requires the inside-out activation of integrins and is characterized by the segregation of leukocyte functionassociated antigen-1 (LFA-1) into a stable peripheral supramolecular adhesion complex (pSMAC). Therefore, we compared the formation of the mature IS in WT and $\mathrm{WASp}^{-1-} \mathrm{B}$ cells after settling on planar lipid bilayers containing anti-BCR with or without ICAM-1. We observed that WT and $\mathrm{WASp}^{-1-} \mathrm{B}$ cells were able to aggregate activating antibody into a cSMAC to a similar extent, both in the presence and absence of ICAM-1 (Figure 6A,B). However, in the presence of ICAM-1, WT B cells exhibited an increased contact area, shown by IRM, as a result of forming a stable pSMAC (Figure 6A,D). In contrast, $\mathrm{WASp}^{-1-} \mathrm{B}$ cells were unable to increase their contact area in the presence of ICAM-1 and were significantly impaired in the formation of the mature IS as a result of their inability to aggregate LFA-1 into a stable pSMAC (Figure 6A,C-E). These findings indicate that $\mathrm{WASp}^{-1-} \mathrm{B}$ cells exhibit defective BCR-mediated inside-out integrin signaling. This impairment in integrin function could give rise to inadequate retention and/or positioning of $\mathrm{MZ} \mathrm{B}$ cells and may explain the decreased MZ B-cell population.

\section{WASp $^{+}$human B cells exhibit a selective advantage in vivo}

To begin to determine whether our observations in this murine model were relevant to human B-cell homeostasis, we initially analyzed WASp expression in peripheral B-cell subsets derived from healthy persons. As described previously, immature/ transitional, naive-mature, and $\operatorname{IgM}^{+}$memory $\mathrm{B}$ cells can be identified by relative staining for CD38, CD24, CD10, and IgM in human peripheral blood ${ }^{30}$ (Figure 7A). Using these markers in association with intracellular WASp staining, we analyzed expression of WASp in human peripheral B-cell subsets. Consistent with work suggesting that $\operatorname{IgM}^{+}$memory B cells represent the functional equivalent of murine MZ B cells, ${ }^{31}$ this population exhibited a significantly higher level of WASp expression in comparison with either transitional or mature, naive human B cells (Figure 7B).

We also analyzed the percentage of $\mathrm{WASp}^{+} \mathrm{B}$ cells within a WAS patient with a revertant mutation affecting a common lymphoid progenitor. ${ }^{32}$ This patient, similar to other older WAS patients, exhibited marked lymphopenia with only approximately $1 \% \mathrm{~B}$ cells present in his peripheral blood. However, we readily observed a significant increase in the relative number of circulating $\mathrm{WASp}^{+} \mathrm{B}$ cells with maturation: within immature B cells, less than $1 \%$ expressed WASp, and this percentage increased in mature B cells and was highest in memory B cells (Figure 7C,D). This result strongly suggests that, consistent with our results in mice, WASp expression leads to a selective advantage for mature peripheral B-cell stages in humans.

\section{Discussion}

WASp is expressed in all nonerythroid derived hematopoietic lineages, including B, T, and NK cells, as well as dendritic cells, neutrophils, and other myeloid-derived populations. These cell populations function in concert in an interactive network to mediate both innate and adaptive immune responses. Thus, to understand the contribution of a specific cell lineage to the clinical phenotype in WAS, it is crucial to use models capable of identifying cell intrinsic functional responses.
Figure 6. WASp is required for integrin activation and pSMAC formation at the B-cell immunologic synapse. WT and WASp ${ }^{-1-}$ B cells were settled onto lipid bilayers containing anti-kappa antibody (green) or antikappa and Alexa532-conjugated ICAM-1 (red) and imaged by confocal microscopy after 20 minutes of interaction. (A) Differential interference contrast (DIC), fluorescence and interference reflection microscopy (IRM) images of representative cells are shown. Quantification of the percentage of $B$ cells forming $(B)$ a cSMAC or (C) an IS (cSMAC + pSMAC) and (D,E) the area of $\mathrm{B}$-cell contact with the bilayer. For each condition, a total of 20 to 50 B cells were analyzed. Bars represent mean values plus or minus SEM. Data are representative of 2 independent experiments. Scale bar represents $2.5 \mu \mathrm{m} .{ }^{* * *} P<.001$.
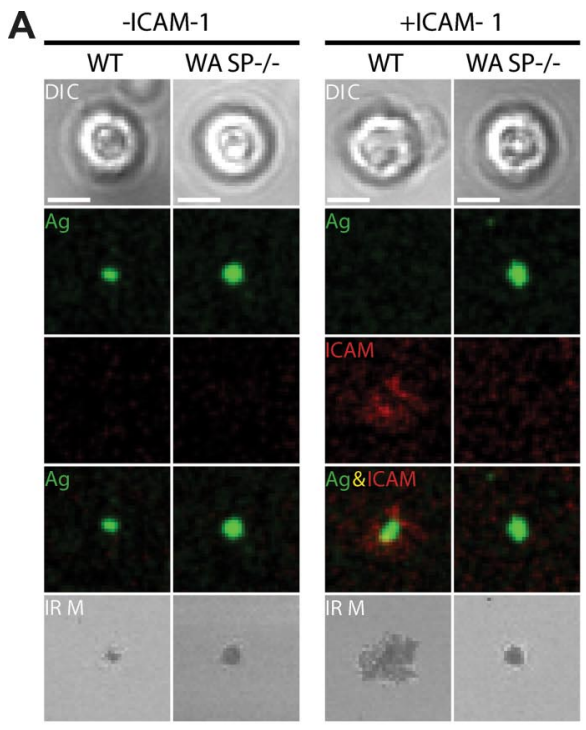

B

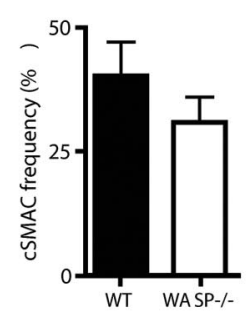

D

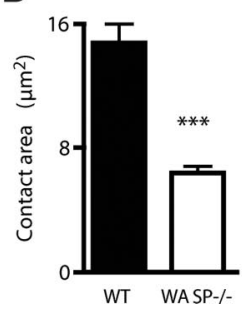

C

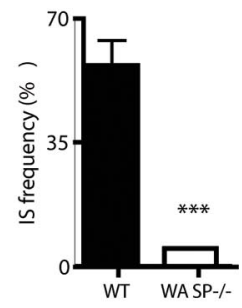

E

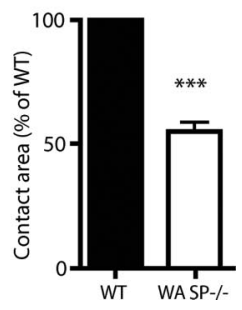


From bloodjournal.hematologylibrary.org by FREDERIC BARON on January 26, 2012. For personal use only.
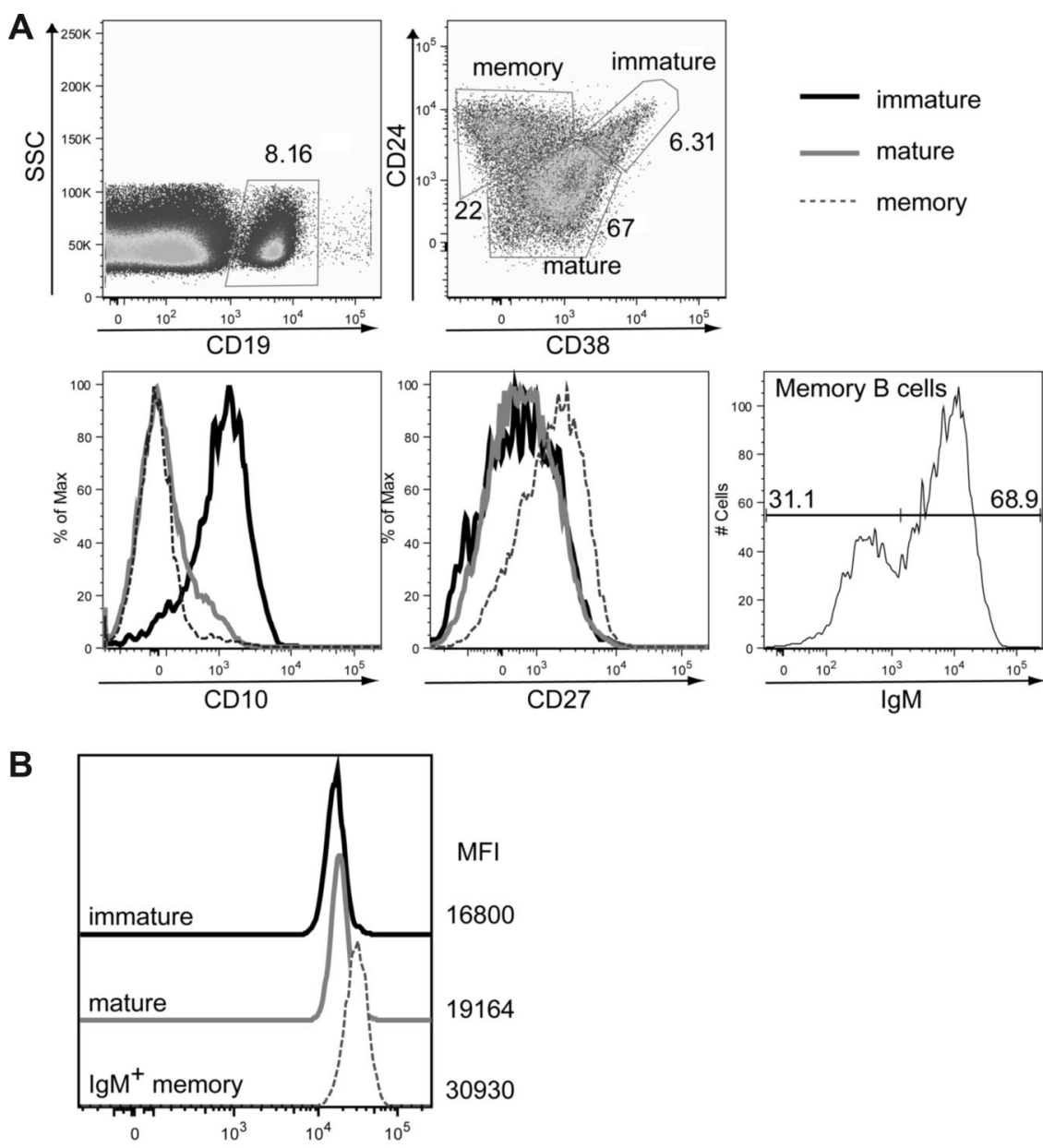

C
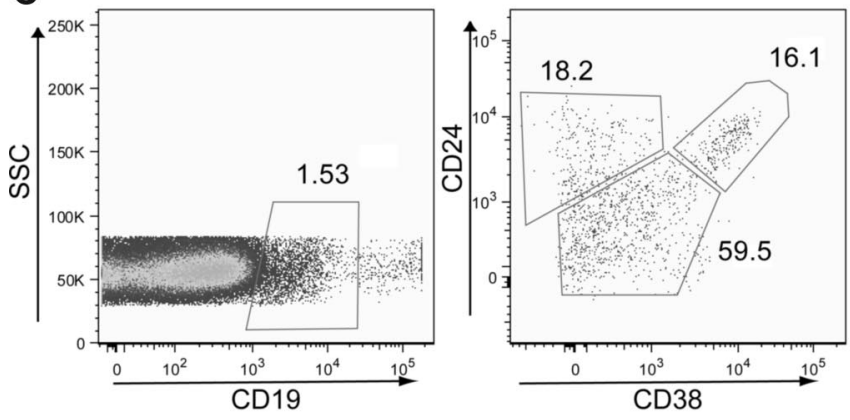

D

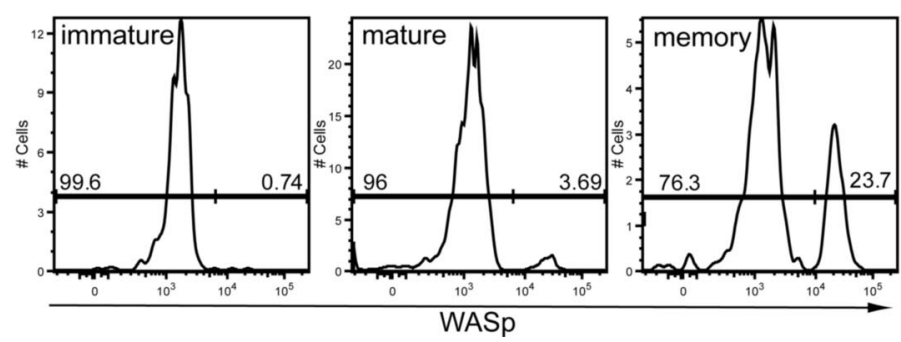

In the current study, we analyzed the phenotype of key B lymphoid compartments within $\mathrm{WASp}^{-1-}$ mice. Our data demonstrate that central BM B-cell development is normal in $\mathrm{WASp}^{-1-}$ mice. In contrast, the mature, peripheral B-cell compartment exhibits marked alterations with a reduction in the absolute numbers of splenic MZP/MZ B cells, peritoneal B1a B cells, and
Figure 7. WASp+ mature B cells exhibit a selective advantage in humans. $(A, B)$ Expression of WASp in immature, mature, and IgM memory $B$ cells in peripheral blood from a healthy person. Peripheral blood mononuclear cells from a healthy person were stained for CD19, CD24, CD38, CD10, CD27, and IgM in addition to WASp. (A) Based on these markers, the following B-cell subsets were identified: $C D 19^{+} \mathrm{CD} 24^{\text {hi }} \mathrm{CD} 38^{\text {hi }}$ immature/ transitional $\mathrm{B}$ cells, CD19 ${ }^{+} \mathrm{CD} 24^{\text {low }} \mathrm{CD} 38^{\text {int }}$ naive mature $B$ cells, and $\mathrm{CD}_{19}{ }^{+} \mathrm{CD} 24^{\text {hi }} \mathrm{CD} 38^{\text {low }}$ lgM ${ }^{+}$IgM memory $B$ cells. Transitional B cells express high levels of CD10, whereas memory B cells express high levels of CD27. (B) WASp expression and relative mean fluorescent intensity are shown for each of these B-cell subsets. Data shown are representative of more than 3 healthy persons. (C,D) Analysis of B cells in a WAS patient with a revertant mutation. B-cell subsets and relative WASp expression were determined in a WAS patient with a known revertant mutation. (C) B-cell subsets were identified as described for panel A. (D) WASp expression in immature, mature, and memory $B$ cells (gated as in panel A) from the WAS patient. 
a selective advantage for $\mathrm{WASp}^{+} \mathrm{B}$ cells beyond the early transitional (T1) B-cell stage. Our analysis further suggests that this phenotype is caused by a homeostatic defect. Finally, analysis of peripheral blood from normal persons and a WAS patient with a revertant mutation indicates that key observations derived from the murine knockout model mirror the role for WASp in human B-cell function.

Our data complement and extend previously published results $^{12,13}$ suggesting that WASp expression was largely dispensable for early B-cell development. We observe no difference in the number or phenotype of BM B-cell developmental subsets or early transitional (T1) B cells in the spleen in $\mathrm{WASp}^{-1-}$ versus WT mice; or in chimeric $\mu \mathrm{MT}$ recipient mice transplanted with WT versus $\mathrm{WASp}^{-1-} \mathrm{BM}$ cells. In addition and consistent with this, there was no selective advantage of $\mathrm{WASp}^{+} \mathrm{B}$ cells at these developmental stages in WASp heterozygous mice. In contrast to our findings, a previous study suggested that $\mathrm{WASp}^{+} \mathrm{BM}$ cells exhibit a selective advantage in transplantation models because of defective chemotaxis in WASp ${ }^{-1-}$ cells. ${ }^{33}$ Whereas this difference may reflect alternative methods for transplant conditioning, our analysis of WASp heterozygous mice has failed to identify any significant selective advantage for lineage-negative, hematopoietic stem cells or BM derived myeloid cells ${ }^{32}$ (A. Astrakhan and D.J.R., unpublished results, 2008).

We show that WASp expression increases after the early transitional B-cell stage to reach its highest expression level in MZP, MZ, and B1a B cells. This increase in WASp expression is associated with a progressive selective advantage of $\mathrm{WASp}^{+}$over $\mathrm{WASp}^{-} \mathrm{B}$ cells and a decrease in cell numbers from the late transitional stage to the MZ B-cell compartment. This selective advantage is most evident in experiments analyzing B-cell intrinsic function: recipients of $\mathrm{WASp}^{-1-} \mathrm{BM}$ exhibited significantly fewer $\mathrm{T} 2$, MZP, and MZ B cells resulting in absolute reduction in the total number of splenic $\mathrm{B}$ cells. In contrast, $\mathrm{WASp}^{-/-}$mice exhibit a specific deficit in splenic MZP and MZ B cells, whereas the number of $\mathrm{T} 2$ cells is normal and the number of T1 B cells is modestly increased. This latter difference might reflect a B-cell extrinsic effect. Whereas we used young mice (6-8 weeks old) for all experiments, we cannot exclude that subclinical inflammatory processes might influence the B-cell phenotype in the $\mathrm{WASp}^{-1-}$ mouse model. In contrast, such factors are largely excluded in the transplant experiments because very few non-B cells are WASpdeficient in this model. Notably, whereas the absolute number of splenic FM B cells was normal in both $\mathrm{WASp}^{-1-}$ mice and in our chimeric transplantation model, we readily observed reductions in mature recirculating B-cell numbers in the BM in both models. This suggests that, whereas ongoing homeostatic signals may be sufficient to maintain splenic FM B-cell numbers (as discussed in greater detail later in "Discussion"), BM recirculating B cells and naive B cells in other lymphoid compartments are probably more sensitive to cell loss.

The peritoneal B1 cell compartment was previously described as unaltered in $\mathrm{WASp}^{-1-}$ mice. ${ }^{12}$ In contrast, whereas there was no difference in B1 progenitors in the BM, we observed a significant decrease in both percentage and absolute number of B1a cells; and a strong selective advantage for WASp-expressing B1a and B1b cells. B1a B cells are crucial for protection against $S$ pneumonia. ${ }^{34}$ Thus, the increased susceptibility of WAS patients to encapsulated bacteria, which has also been described in $\mathrm{WASp}^{-1-}$ mice, ${ }^{35}$ may be largely explained by the reduced number of both $\mathrm{MZ}$ and $\mathrm{B} 1 \mathrm{a}$ $\mathrm{B}$ cells. Consistent with these data, a recent study also demonstrated altered TI-type 2 immune responses in this strain. ${ }^{8}$
Importantly, several key features of our analysis were similar in both murine and human B cells. WASp expression was increased in mature versus immature/transitional human B cells and was highest in $\mathrm{IgM}^{+}$memory B cells, the functional, and possibly developmental, equivalent of murine MZ B cells. ${ }^{31}$ Moreover, analyzing blood from a WAS patient with a revertant mutation, we observed a proportional increase in $\mathrm{WASp}^{+}$cells in mature versus transitional B cells and further enrichment within the memory B-cell compartment, findings consistent with a selective advantage for WASp ${ }^{+}$ follicular mature and memory B cells. Although we were unable to identify an enrichment of $\mathrm{WASp}^{+} \mathrm{B}$ cells within the $\mathrm{IgM}^{+}$ memory compartment, the very low absolute numbers of total and $\operatorname{IgM}^{+}$memory B cells significantly limited this analysis. It is also possible that $\mathrm{WASp}^{+}$human $\mathrm{IgM}^{+}$memory $\mathrm{B}$ cells are preferentially localized to lymphoid compartments not available in our analysis.

Overall, our phenotypic data in humans and mice are in accord with previous studies in WAS: the number of total B cells and MZ B cells are decreased in both human WAS patients and WASp ${ }^{-1-}$ mice ${ }^{4,8,13,19}$; and similar to our observations in mice, a previous study also suggests that the relative percentage of immature peripheral B cells is increased in WAS patients. ${ }^{36}$

Our data clearly define the late transitional stage as the point at which WASp expression becomes crucial for B-cell function. We also addressed the critical question as to whether this reflects a developmental versus homeostatic defect. We excluded that impaired Notch signaling is the major reason for a diminished MZ B-cell compartment. Using in vivo BrdU labeling, we demonstrate significantly higher BrdU incorporation in splenic B-cell subsets, recirculating BM B cells, as well as B1 B cells, findings consistent with a higher turnover rate for each of these subpopulations. Notably, the absolute number of $\mathrm{BrdU}^{+} \mathrm{MZ} \mathrm{B}$ cells was equal or even slightly higher in $\mathrm{WASp}^{-/-}$versus WT mice. This latter finding essentially excludes a developmental defect because the number of newly generated MZ B cells is comparable. Moreover, cell-cycle analysis revealed an increase in cycling cells ( $\mathrm{S}$ - and $\mathrm{G}_{2} / \mathrm{M}$-phase) in nearly all peripheral B-cell subsets in WASp ${ }^{-/-}$ mice. This feature was most pronounced in T2 B cells, the subset that is most highly responsive to homeostatic signals. ${ }^{25}$ These coordinate findings suggest that an increase in newly generated B cells can partially compensate for homeostatic cell losses that occur in WASp ${ }^{-1-}$ mice. Such compensation appears most efficient within the FM B-cell pool as overall FM B-cell numbers are not significantly reduced in $\mathrm{WASp}^{-1-}$ mice.

Having excluded a developmental defect, we also tested whether key B cell-intrinsic survival signals might be selectively impaired in $\mathrm{WASp}^{-1-}$ mice. Previous reports have suggested an increased rate of spontaneous apoptosis in human B cells derived from peripheral blood of WAS patients. ${ }^{26,37}$ However, conclusions from these and other studies using B cells from $\mathrm{WASp}^{-1-}$ mice are difficult to interpret because nearly all were performed using heterogeneous populations or cell lines. BCR and BAFF-R signals coordinately provide the crucial homeostatic and survival signals for late transitional and mature B cells. ${ }^{38}$ Therefore, we tested both basal and/or receptor-mediated survival signals using highly purified, WT versus $\mathrm{WASp}^{-1-}$ B-cell subsets. We were unable to identify any alterations in basal or receptor-triggered signals, including no differences in: relative receptor expression, cell survival, antiapoptotic signaling, Akt activation, or p100 processing.

The absence of a survival defect in $\mathrm{WASp}^{-1-} \mathrm{B}$ cells suggests that alternative defects in homeostasis probably account for the observed losses within the mature B-cell compartment. A previous 
study has shown a requirement for Pyk-2 driven, chemokine responses in $\mathrm{MZ}$ B-cell development, ${ }^{39}$ and recent work has identified defects in chemokine-driven $\mathrm{WASp}^{-1-} \mathrm{B}$-cell migration. ${ }^{18}$ However, because the initial pool of both MZ precursor and mature $\mathrm{MZ} \mathrm{B}$ cells is intact in $\mathrm{WASp}^{-/-}$mice, altered migration alone seems doubtful to explain the selective loss of these subsets. Instead, we predict that signals that promote retention of MZP/MZ $\mathrm{B}$ cells within the $\mathrm{MZ}$ niche are probably deficient in $\mathrm{WASp}^{-1-}$ animals. MZ B-cell localization requires up-regulation of LFA-1 and $\alpha 4 \beta 1$ integrins as well as signaling via Sphingosine-1phosphate (S1P) receptors. ${ }^{29,40-42}$ Transcript levels for $\mathrm{S} \mathrm{P}_{3}$, but not $\mathrm{S}_{1} \mathrm{P}_{1}$, were significantly decreased in MZ B cells from WASp ${ }^{-/-}$ mice (Figure $\mathrm{S} 4$ ). However, because $\mathrm{S}_{1} \mathrm{P}_{3}$-deficient mice exhibit normal MZ B-cell numbers, ${ }^{41,42}$ this observation alone cannot explain MZ B cell losses. In addition, WASp ${ }^{-1-}$ MZ B cells express normal levels of LFA-1 and CD62L (data not shown) and show comparable ICAM-1 and VCAM-1 binding. ${ }^{8}$

Integrin signals are crucial for the retention of B cells within the MZ. ${ }^{29}$ Further, integrin binding can be directly influenced by BCR signaling, and such changes are probably important in regulating the MZ B-cell compartment. Using lipid bilayers, we show that $\mathrm{WASp}^{-1-} \mathrm{B}$ cells are able to aggregate antigen into cSMACs after receptor stimulation. However, WASp ${ }^{-1-} \mathrm{B}$ cells exhibit a nearcomplete deficit in integrin clustering in response to BCR and ICAM costimulation, as demonstrated by the failure to generate a stable pSMAC or to increase the cell:lipid bilayer contact area. BCR-driven signals promote a change from a low to high avidity integrin binding state, thereby enhancing B-cell adherence to local adhesion molecules. ${ }^{43}$ We hypothesize that the deficit in inside-out signaling shown herein limits retention of $\mathrm{WASp}^{-1-} \mathrm{MZ} \mathrm{B}$ cells and thereby promotes MZ B-cell loss via reduced access to microenvironmental survival signals. This retention deficit probably also impacts additional WASp ${ }^{-1-}$ mature B-cell subsets. Thus, our combined data best support a model in which inefficient localization of B cells within key niches leads to an ongoing homeostatic defect. Direct measurement of integrin affinity in resting versus stimulated MZ B cells, as well as studies of in vivo positioning, are required to fully address this question.
In conclusion, the current study precisely defines the B-cell intrinsic defects in WASp deficiency. This work sets the stage for a better understanding of the clinical phenotype of WAS and provides new insight into the regulation of the mature peripheral B-cell compartment. In addition, we show, for the first time, that $\mathrm{WASp}^{+}$human and murine B cells exhibit a strong selective advantage. These observations suggest that future gene therapy strategies, leading to sustained endogenous levels of WASp expression in B lineage cells, might rescue these homeostatic defects and promote improved humoral immunity in WAS.

\section{Acknowledgments}

The authors thank Dr Hans Ochs for his generous gift of WASp antibody, and gratefully acknowledge members of the Rawlings laboratory for helpful discussions.

This work was supported by the National Institutes of Health (grants HD37091 and AI071163), the National Institutes of HealthUSIDNet (a pilot award), the Elizabeth Campbell Endowment, Cancer Reseach UK, and the Wellcome Trust.

\section{Authorship}

Contribution: A.M.-B. and S.B.-H. designed and performed research, analyzed data, and wrote the paper; S.H.-B. designed and performed research and analyzed data; S.K. was a technical assistant and also provided animal husbandry; M.W. designed and performed research and analyzed data; F.D.B. designed research and analyzed data; G.B. and A.J.T. designed research and contributed mice; and D.J.R. designed research, analyzed data, and wrote the paper.

Conflict-of-interest disclosure: The authors declare no competing financial interests.

Correspondence: David J. Rawlings, Center for Immunity and Immunotherapies, Seattle Children's Hospital Research Institute, 1900 Ninth Avenue, Seattle, WA 98101; e-mail: drawling@ u.washington.edu.

\section{References}

1. Sullivan KE, Mullen CA, Blaese RM, Winkelstein JA. A multiinstitutional survey of the WiskottAldrich syndrome. J Pediatr. 1994;125:876-885.

2. Ochs HD, Slichter SJ, Harker LA, Von Behrens WE, Clark RA, Wedgwood RJ. The WiskottAldrich syndrome: studies of lymphocytes, granulocytes, and platelets. Blood. 1980;55:243-252.

3. Park JY, Kob M, Prodeus AP, Rosen FS, Shcherbina A, Remold-O'Donnell E. Early deficit of lymphocytes in Wiskott-Aldrich syndrome: possible role of WASP in human lymphocyte maturation. Clin Exp Immunol. 2004;136:104-110.

4. Ochs HD, Thrasher AJ. The Wiskott-Aldrich syndrome. J Allergy Clin Immunol. 2006;117:725738; quiz 739.

5. Thrasher AJ. WASp in immune-system organization and function. Nat Rev Immunol. 2002;2:635646.

6. Snapper SB, Meelu P, Nguyen D, et al. WASP deficiency leads to global defects of directed leukocyte migration in vitro and in vivo. J Leukoc Biol. 2005;77:993-998.

7. Gallego MD, de la Fuente MA, Anton IM, Snapper S, Fuhlbrigge R, Geha RS. WIP and WASP play complementary roles in T cell homing and chemotaxis to SDF-1alpha. Int Immunol. 2006;18: 221-232.
8. Westerberg L, Larsson M, Hardy SJ, Fernandez C, Thrasher AJ, Severinson E. Wiskott-Aldrich syndrome protein deficiency leads to reduced B-cell adhesion, migration, and homing, and a delayed humoral immune response. Blood. 2005; 105:1144-1152.

9. Zhang H, Schaff UY, Green CE, et al. Impaired integrin-dependent function in Wiskott-Aldrich syndrome protein-deficient murine and human neutrophils. Immunity. 2006;25:285-295.

10. Dupre L, Aiuti A, Trifari S, et al. Wiskott-Aldrich syndrome protein regulates lipid raft dynamics during immunological synapse formation. Immunity. 2002;17:157-166.

11. Gallego MD, Santamaria M, Pena J, Molina IJ. Defective actin reorganization and polymerization of Wiskott-Aldrich T cells in response to CD3-mediated stimulation. Blood. 1997;90:3089-3097.

12. Snapper SB, Rosen FS, Mizoguchi E, et al. Wiskott-Aldrich syndrome protein-deficient mice reveal a role for WASP in T but not B cell activation. Immunity. 1998;9:81-91.

13. Zhang J, Shehabeldin A, da Cruz LA, et al. Antigen receptor-induced activation and cytoskeletal rearrangement are impaired in Wiskott-Aldrich syndrome protein-deficient lymphocytes. J Exp Med. 1999;190:1329-1342.
14. Molina IJ, Sancho J, Terhorst C, Rosen FS, Remold-O'Donnell E. T cells of patients with the Wiskott-Aldrich syndrome have a restricted defect in proliferative responses. J Immunol. 1993; 151:4383-4390.

15. Facchetti F, Blanzuoli L, Vermi W, et al. Defective actin polymerization in EBV-transformed B-cell lines from patients with the Wiskott-Aldrich syndrome. J Pathol. 1998;185:99-107.

16. Henriquez NV, Rijkers GT, Zegers BJ. Antigen receptor-mediated transmembrane signaling in Wiskott-Aldrich syndrome. J Immunol. 1994;153: 395-399.

17. Simon HU, Mills GB, Hashimoto S, Siminovitch KA. Evidence for defective transmembrane signaling in B cells from patients with Wiskott-Aldrich syndrome. J Clin Invest. 1992;90:1396-1405.

18. Westerberg L, Greicius G, Snapper SB, Aspenstrom P, Severinson E. Cdc42, Rac1, and the Wiskott-Aldrich syndrome protein are involved in the cytoskeletal regulation of B lymphocytes. Blood. 2001;98:1086-1094.

19. Vermi W, Blanzuoli L, Kraus MD, et al. The spleen in the Wiskott-Aldrich syndrome: histopathologic abnormalities of the white pulp correlate with the clinical phenotype of the disease. Am J Surg Pathol. 1999;23:182-191. 
From bloodjournal.hematologylibrary.org by FREDERIC BARON on January 26, 2012. For personal use only.

20. Carrasco YR, Fleire SJ, Cameron T, Dustin ML, Batista FD. LFA-1/ICAM-1 interaction lowers the threshold of $B$ cell activation by facilitating $B$ cell adhesion and synapse formation. Immunity. 2004;20:589-599.

21. Fleire SJ, Goldman JP, Carrasco YR, Weber M, Bray D, Batista FD. B cell ligand discrimination through a spreading and contraction response. Science. 2006;312:738-741.

22. Li YS, Hayakawa K, Hardy RR. The regulated expression of $B$ lineage associated genes during $B$ cell differentiation in bone marrow and fetal liver. J Exp Med. 1993;178:951-960.

23. Montecino-Rodriguez $E$, Leathers $H$, Dorshkind $\mathrm{K}$. Identification of a B-1 B cell-specified progenitor. Nat Immunol. 2006;7:293-301.

24. Saito T, Chiba S, Ichikawa M, et al. Notch2 is preferentially expressed in mature B cells and indispensable for marginal zone $\mathrm{B}$ lineage development. Immunity. 2003;18:675-685.

25. Meyer-Bahlburg A, Andrews SF, Yu KO, Porcelli SA, Rawlings DJ. Characterization of a late transitional B-cell population highly sensitive to BAFF-mediated homeostatic proliferation. J Exp Med. 2008;205:155-168.

26. Rawlings SL, Crooks GM, Bockstoce D, Barsky LW, Parkman R, Weinberg KI. Spontaneous apoptosis in lymphocytes from patients with WiskottAldrich syndrome: correlation of accelerated cell death and attenuated bcl-2 expression. Blood. 1999;94:3872-3882.

27. Su TT, Guo B, Wei B, Braun J, Rawlings DJ. Signaling in transitional type $2 \mathrm{~B}$ cells is critical for peripheral B-cell development. Immunol Rev. 2004;197:161-178.

28. Donahue AC, Fruman DA. Distinct signaling mechanisms activate the target of rapamycin in response to different B-cell stimuli. Eur J Immunol. 2007;37:2923-2936.

29. Lu TT, Cyster JG. Integrin-mediated long-term $B$ cell retention in the splenic marginal zone. Science. 2002;297:409-412.

30. Cuss AK, Avery DT, Cannons JL, et al. Expansion of functionally immature transitional $B$ cells is associated with human-immunodeficient states characterized by impaired humoral immunity. J Immunol. 2006;176:1506-1516.

31. Kruetzmann S, Rosado MM, Weber H, et al. Human immunoglobulin $\mathrm{M}$ memory $\mathrm{B}$ cells controlling Streptococcus pneumoniae infections are generated in the spleen. J Exp Med. 2003;197: 939-945.

32. Humblet-Baron S, Sather B, Anover S, et al. Wiskott-Aldrich syndrome protein is required for regulatory T cell homeostasis. J Clin Invest. 2007;117: 407-418.

33. Lacout C, Haddad E, Sabri S, et al. A defect in hematopoietic stem cell migration explains the nonrandom X-chromosome inactivation in carriers of Wiskott-Aldrich syndrome. Blood. 2003; 102:1282-1289.

34. Haas KM, Poe JC, Steeber DA, Tedder TF. B-1a and $\mathrm{B}-1 \mathrm{~b}$ cells exhibit distinct developmental requirements and have unique functional roles in innate and adaptive immunity to $S$. pneumoniae. Immunity. 2005;23:7-18.

35. Andreansky S, Liu H, Turner S, et al. WASP. mice exhibit defective immune responses to influenza A virus, Streptococcus pneumoniae, and Mycobacterium bovis BCG. Exp Hematol. 2005; 33:443-451

36. Park JY, Shcherbina A, Rosen FS, Prodeus AP, Remold-O'Donnell E. Phenotypic perturbation of $B$ cells in the Wiskott-Aldrich syndrome. Clin Exp Immunol. 2005;139:297-305.

37. Rengan R, Ochs HD, Sweet LI, et al. Actin cytoskeletal function is spared, but apoptosis is increased, in WAS patient hematopoietic cells. Blood. 2000;95:1283-1292.

38. Rathmell JC. B-cell homeostasis: digital survival or analog growth? Immunol Rev. 2004;197:116-128.

39. Guinamard R, Okigaki M, Schlessinger J, Ravetch JV. Absence of marginal zone B cells in Pyk-2-deficient mice defines their role in the humoral response. Nat Immunol. 2000;1:31-36.

40. Lo CG, Lu TT, Cyster JG. Integrin-dependence of lymphocyte entry into the splenic white pulp. J Exp Med. 2003;197:353-361.

41. Cinamon G, Matloubian M, Lesneski MJ, et al Sphingosine 1-phosphate receptor 1 promotes $B$ cell localization in the splenic marginal zone. Nat Immunol. 2004;5:713-720.

42. Girkontaite I, Sakk V, Wagner M, et al. The sphingosine-1-phosphate (S1P) lysophospholipid receptor S1P3 regulates MAdCAM-1 + endothelial cells in splenic marginal sinus organization. J Exp Med. 2004;200:1491-1501.

43. Carrasco YR, Batista FD. B cell recognition of membrane-bound antigen: an exquisite way of sensing ligands. Curr Opin Immunol. 2006;18: 286-291. 